\title{
The lack of an association between Body Image Satisfaction and Self-Esteem in high school students in Eastern Croatia: A cross-sectional study
}

Zvonimir Bosnic ( $\sim$ zbosnic191@gmail.com )

Sveuciliste J J Strossmayera u Osijeku

Maja Miletic

Sveuciliste J J Strossmayera u Osijeku

Nikola Volaric

Sveuciliste J J Strossmayera u Osijeku

Dubravka Holik

Sveuciliste J J Strossmayera u Osijeku

Mile Volaric

Sveuciliste J J Strossmayera u Osijeku

Ljiljana Trtica Majnaric

Sveuciliste Josipa Jurja Strossmayera u Osijeku Medicinski Fakultet Osijek

Research article

Keywords: degree of self-esteem, body image satisfaction, BMI, gender, adolescents, socioeconomic factor

Posted Date: September 14th, 2020

DOl: https://doi.org/10.21203/rs.3.rs-57514/v2

License: (c) (i) This work is licensed under a Creative Commons Attribution 4.0 International License. Read Full License 


\section{Abstract}

Introduction: The research objectives are to examine the degree of satisfaction of students in two high schools in Eastern Croatia, regarding their physical appearance and self-esteem based on their gender and type of school - Grammar school or Vocational school. Furthermore, it aims to determine the correlation between degree of satisfaction regarding physical appearance and self-esteem and examines the differences in socio-economic status among the students of the two schools.

Methods: The study is designed as a cross-sectional research performed in the Secondary Health and Veterinary School and Grammar School in Vinkovci. The study includes 278 participants. The data were collected in three ways. First, by using a survey on socio-economic status of the participants. Second, a modified test consisting of fourteen questions was used to examine the level of body image satisfaction. Third, a test consisting of ten questions was used to examine the level of self-esteem.

Results: Median age of participants is 18 years. The research established a linear correlation between the body image satisfaction and gender of the students in both schools. An association between level of body image satisfaction and self-esteem was not established.

Conclusion: To conclude with, adolescents in this region of Croatia are not overly concerned about their physical appearance despite relatively decreased self-esteem. A lack of association between reduced selfesteem and self-assessment of appearance may also be a consequence of later sexual maturation and tradional development which promote the traditional values of family, youth life and marriage

\section{Plain English Summary}

Adolescence is a sensitive period of life when many factors can affect their well-being and mental development. A body image is an important factor in the development of self- esteem. Previous knowledge gained so far indicated the close associatios between satisfaction with body shape image and self-esteem in adolescents. Disorted self image and self esteem is a key factor in the development of eating disorders and other psychological in adolescents. In our research, we aimed to asess the association between the real BMI values and the body image in adolescents in our surrounding. The study includes 278 participants. The research established a linear correlation between the body image satisfaction and gender of the students in both schools. An association between level of body image satisfaction and self-esteem was not established. Early detection of a negative body image could provide a better control over self- esteem and promote psychological support later and contribute overall better quality of life.

\section{Introduction}

Great number of adolescents face problems related to physical appearance and social contact due to the omnipresence of media and growing availability of social media (1). Developed countries promote slim body as an ideal image of physical appearance. In addition, recent research show that less developed 
countries adopt this western culture what causes an increase in number of eating disorder cases (2). This ideal slim female body is an unreachable goal for many girls and women so they apply extreme starvation, regurgitation, laxatives, weight loss pills and similar methods for losing body weight $(3,4)$. Even dough the girls are those who struggle the most with issues related to body image and self-esteem, there are many young boys, between 14 and 16 years of age, who go through similar crisis (5). Promoting the importance of such slim physical appearance leads to dissatisfaction with ones' body, low selfesteem and pathological attempts to reach the goal of a slim and perfect body (6). Puberty is a very sensitive period when many experience increase in body weight. Therefore, drastic changes related to the body or body parts become one of the main preoccupations. Furthermore, adolescents begin to compare themselves to other people in their surroundings and, in that way, they experience increased social and academic pressure. Nevertheless, numerous factors affect the development of body image dissatisfaction. Apart from biological factors such as age, gender, stages of puberty and body mass index (BMI), there are sociocultural factors that influence one's mindset. These factors determine which physical characteristics are desirable and which are not. In order to determine ideal anthropometric measures, one of the principal tools is BMI, which is used to define the levels of nutritional status. Despite its availability, it has been used mostly for adults so there was need for different measurement tools ( 7 , 8). Family is considered to be the first context for a child's development and family members and friends are the strongest social support for adolescents. Nevertheless, it is possible that there are some negative events, such as teasing and pressuring to change physical appearance, which affect the mindset of the adolescent. According to the approach of social comparison, the risk of body image dissatisfaction is

greater with those who compare themselves to others than with those who rarely compare themselves to others. Moreover, according to the sociocultural approach, factors like the press and visual media are the source of strong messages about the physical characteristics that are acceptable. Therefore, the objective of this research is to determine the levels of satisfaction regarding physical appearance and self-esteem among students in the final years of their high school education. In addition, it investigates the association between the level of satisfaction and self-esteem and differences in socioeconomic status of the students.

\section{Materials And Methods}

\section{Design:}

This study has been conducted as a cross-sectional study and has been conducted anonymously in two high schools in Eastern Croatia, in small town Vinkovci, which presents a typical tradional and conservative town in Croatia, that could promote different understanding of the perfect body measures.

\section{Participants:}

There are 278 participants, 159 of whom are students of Secondary Health and Veterinary School (nurses, veterinarian technicians and physical therapists), and 119 are students in the fourth grade of 
Grammar School (general, linguistic and mathematical grammar school). When it comes to age of the participants, it ranges from 18 to 20 years.

\section{Assessment instructions:}

The questionnaire on socio-economic status of the students has been filled anonymously. It contained 21 closed-ended type questions. Apart from this questionnaire, a modified test, the Body Image Questionnaire, has been used for examining the level of satisfaction regarding physical appearance. It contains 14 questions. In this case, a higher result denotes higher dissatisfaction regarding one's body or particular body part. In addition, a self-esteem test was used. It contains 10 questions and it was anonymous. The participants answered questions about real and desired anthropomorphic measures. The difference between those two estimated notions represents the level of deviation of the real perception from the ideal perception of one's own body. In other words, it represents individual level of body image dissatisfaction or dissatisfaction with a particular body feature. High level of deviation denotes greater dissatisfaction of the person. Both test are standardized tests. In this case, we have also examined the difference between the measured and self-estimated BMI values. BMI was measured during admission.

\section{Statistics plan:}

In this study, the linear correlation between the level of body image satisfaction and level of self-esteem has been examined using Pearson's correlation coefficient. Moreover, the socio-economic differences that affect these two notions have been analyzed. The results are presented in tables and charts. Categorical data are presented by absolute and relevant frequencies. Differences between categorical data have been tested by $\chi 2$ test and Fisher's exact test. All $p$ values are two-folded. The level of significance is set to $a=0$, 05 . Statistical analysis has been conducted by a statistical program SPSS (version 16.0, SPSS Inc., Chicago, IL, USA) and Microsoft Office Excel Calculation (9).

\section{Results}

When it comes to participants, as previously presented, there are 159 students from medical vocational school and 119 students from grammar school. Median age is 18 (interquartile range is from 18 to 19) for both schools. However, there are 15 students who are 20 years old in medical vocational school, and in grammar school, there is only one student who is 20 years old. There is a statistically relevant difference when it comes to residency. In medical vocational school, there are $180(67,9 \%)$ students who come from villages. On the other hand, in grammar school, there are $69(57,9 \%)$ students who come from towns $\left(\chi^{2}\right.$ test, $\left.p=0,005\right)$ (Table 1$)$. There are no statistically relevant differences in body image satisfaction among medical students when it comes to gender ( $\chi^{2}$ test, $\left.p=0,22\right)$, although there is a noticeable tendency among the female students to worry about their physical appearance. The female participants in grammar school are significantly more concerned about their physical appearance than male participants in the same school $\left(\chi^{2}\right.$ test, $\left.p<0,001\right)$ (Table 2$)$. The results from both school indicate that all students in this research exhibit lower self-esteem (Table 2). 
Table 1. Demographic dana and residency comparison

\begin{tabular}{|c|c|c|c|c|}
\hline & & $\begin{array}{l}\text { medical } \\
\text { vocational school } \\
\mathrm{N}(\%)\end{array}$ & $\begin{array}{l}\text { Grammar } \\
\text { vocational school } \\
\text { N }(\%)\end{array}$ & $P^{*}$ \\
\hline \multirow[t]{2}{*}{ Gender } & Male & $38(23,9)$ & $33(27,7)$ & \\
\hline & Female & $121(76,1)$ & $86(72,3)$ & \\
\hline \multirow[t]{3}{*}{ Age } & 18 years & $82(51,6)$ & $87(73,1)$ & \\
\hline & 19 years & $62(39,0)$ & $31(26,1)$ & \\
\hline & 20 years & $15(9,4)$ & $1(0,8)$ & \\
\hline \multirow[t]{3}{*}{ Residency } & Town & $51(32,1)$ & $69(57,9)$ & 0,005 \\
\hline & Village & $108(67,9)$ & $119(100)$ & \\
\hline & Total & $159(100)$ & $119(100)$ & \\
\hline
\end{tabular}

Table 2. Body image satisfaction among medical students and grammar students in relation to gender 


\begin{tabular}{|c|c|c|c|c|c|c|c|c|}
\hline & \multicolumn{4}{|c|}{ Medical vocational school } & \multicolumn{4}{|c|}{ Grammar school } \\
\hline \multirow[t]{2}{*}{ Body image satisfaction } & \multicolumn{4}{|l|}{$\mathrm{N}(\%)$} & \multicolumn{4}{|l|}{$\mathrm{N}(\%)$} \\
\hline & Male & Female & Total & $\mathrm{P}^{*}$ & Male & Female & Total & $\mathrm{P}^{*}$ \\
\hline $\begin{array}{l}\text { I am very worried about my physical } \\
\text { appearance }\end{array}$ & $\begin{array}{c}3 \\
(7,9)\end{array}$ & $\begin{array}{c}17 \\
(14,0)\end{array}$ & $\begin{array}{c}20 \\
(12,6)\end{array}$ & & $\begin{array}{l}0 \\
(0)\end{array}$ & $\begin{array}{c}14 \\
(16,3)\end{array}$ & $\begin{array}{c}14 \\
(11,8)\end{array}$ & \\
\hline $\begin{array}{l}\text { I am worried to some extent about my } \\
\text { physical appearance }\end{array}$ & $\begin{array}{c}5 \\
(13,2)\end{array}$ & $\begin{array}{c}21 \\
(17,4)\end{array}$ & $\begin{array}{c}26 \\
(16,4)\end{array}$ & & $\begin{array}{c}1 \\
(5,3)\end{array}$ & $\begin{array}{c}18 \\
(20,9)\end{array}$ & $\begin{array}{c}19 \\
(16,0)\end{array}$ & \\
\hline $\begin{array}{l}\text { I am mildly worried about my physical } \\
\text { appearance }\end{array}$ & $\begin{array}{c}6 \\
(15,8)\end{array}$ & $\begin{array}{c}30 \\
(24,8)\end{array}$ & $\begin{array}{c}36 \\
(22,6)\end{array}$ & 0,22 & $\begin{array}{c}6 \\
(18,2)\end{array}$ & $\begin{array}{c}23 \\
(26,7)\end{array}$ & $\begin{array}{c}29 \\
(24,4)\end{array}$ & $<0,001$ \\
\hline I am not worried at all & $\begin{array}{c}25 \\
(63,1)\end{array}$ & $\begin{array}{c}53 \\
(43,8)\end{array}$ & $\begin{array}{c}77 \\
(48,4)\end{array}$ & & $\begin{array}{c}26 \\
(78,8)\end{array}$ & $\begin{array}{c}31 \\
(36,0)\end{array}$ & $\begin{array}{c}57 \\
(47,9)\end{array}$ & \\
\hline total & $\begin{array}{c}38 \\
(100)\end{array}$ & $\begin{array}{l}121 \\
(100)\end{array}$ & $\begin{array}{r}159 \\
(100)\end{array}$ & & $\begin{array}{c}33 \\
(100)\end{array}$ & $\begin{array}{c}86 \\
(100)\end{array}$ & $\begin{array}{c}119 \\
(100)\end{array}$ & \\
\hline
\end{tabular}

$* \chi \square$ test

The linear correlation between degree of satisfaction regarding physical appearance and self-esteem confirmed the association between body image satisfaction and gender of students in medical vocational school $(r=0,157 ; p=0,04)$ and students in grammar school $(r=0,371 ; p<0,001)$. (Table 4). There has been no evidence of relationship between body image satisfaction and level of self-esteem. The majority of male participants in both schools falls into the category with a normal body weight .The majority of female participants in both school falls into the category with a normal body weight, while 24 participants in medical vocational school and 10 participants in grammar school fall into the category with excessive body weight. The majority of female participants in both school falls into the category with a normal body weight, while 24 participants in medical vocational school and 10 participants in grammar school fall into the category with excessive body weight (Figure 1). The participants in medical vocational school are mainly not concerned about their physical appearance. This also includes the students who have expressed a slight concern but they estimated their appearance is in accordance with the desired BMI. When it comes to participants in grammar school, the majority also states they are not worried about their physical appearance and estimate it is in accordance with the desired BMI (Figure 2). In relation to living arraignments, $145(91,2 \%)$ participants from medical vocational school and 100 (91, $6 \%$ ) participants from grammar school live with their parents (Table 4). Another factor that has been 
compared among the students is alcohol consumption. Among the participants in medical vocational school 95 (59,7\%) stated they consume alcohol and 64 (40,3\%) participants answered negative to that question. On the other hand, $77(64,7 \%)$ participants in grammar school answered they consume alcohol and $42(35,3 \%)$ participants do not consume alcohol (Table 5). There is a statistically relevant difference in this comparison of participants. Furthermore, in grammar school, $71(59,7 \%)$ participants consumes alcohol once a week. On the other hand, $85(53,5 \%)$ participants in medical vocational school consumes alcohol once a week. However, $9(5,7 \%)$ participants from medical vocational school consumes alcohol several times a week, and $5(4,2 \%)$ participants from grammar school consumes alcohol several times a week.

Table 3. Linear correlation between body image satisfaction and self-esteem among students of both school in relation to gender

\begin{tabular}{|l|l|l|l|}
\hline Medical vocational school & Grammar school & Pearson's correlation coefficient, $\mathrm{P}$ & P value \\
\hline Body image satisfaction & Body image satisfaction & 0,033 & 0,72 \\
\hline Self-esteem & Self-esteem & $-0,052$ & 0,57 \\
\hline Body image satisfaction & Self-esteem & $-0,012$ & 0,689 \\
\hline Medical vocational school & Medical vocational school & & 0,65 \\
\hline Body image satisfaction & Self-esteem & $-0,036$ & 0,04 \\
\hline Body image satisfaction & Gender & 0,157 & 0,17 \\
\hline Self-esteem & Gender & 0,108 & 0,41 \\
\hline Grammar school & Grammar school & & $<0,001$ \\
\hline Body image satisfaction & Self-esteem & $-0,076$ & 0,27 \\
\hline Body image satisfaction & Gender & 0,371 & \\
\hline Self-esteem & Gender & $-0,101$ & \\
\hline
\end{tabular}

$* \chi \square$ test

Table 4. Comparison between students in relation to living arraignments 


\begin{tabular}{|l|l|l|l|}
\hline \multirow{2}{*}{ Parental status } & \multicolumn{2}{|l|}{ N (\%) } & \multirow{2}{*}{ P* } \\
\cline { 2 - 3 } & \multicolumn{2}{|l|}{ Medical vocational school } & \\
\hline Both parents & $145(91,2)$ & $109(91,6)$ & \multirow{2}{*}{0,23} \\
\hline Divorced parents & $8(5,0)$ & $10(8,4)$ & \\
\hline Single parent & $6(3,8)$ & $0(0)$ & \\
\hline Total & $159(100)$ & $119(100)$ & \\
\hline
\end{tabular}

$*_{\chi \square}$ test

Table 5. Alcohol consumption comparison between the two schools

\begin{tabular}{|c|c|c|c|}
\hline \multirow[t]{2}{*}{ Alcohol consumption } & \multicolumn{2}{|l|}{ N (\%) } & \multirow[t]{2}{*}{$\mathrm{P}^{*}$} \\
\hline & Medical vocational school & Grammar school & \\
\hline Yes & $95(59,7)$ & $77(64,7)$ & 0,77 \\
\hline No & $64(40,3)$ & $42(35,3)$ & \\
\hline Total & $159(100)$ & 119 (100) & \\
\hline
\end{tabular}

\section{Discussion}

The body is the most prominent feature of a person. That is why one's perception of their own body has a significant role in forming general self-esteem. Furthermore, today's societies promote the importance of attractive physical appearance. Given the overwhelming prevalence of thin and lean female and strong and lean male images in social media common to all westernized societies, body image concerns have become widespread among adolescents. Moreover, statements on what is acceptable when it comes to physical appearance permeate post-industrial cultures (10). As beauty industry grows, there are numerous possibilities and methods to form one's body to fit the promoted ideas of physical beauty. 
Furthermore, in many parts of the world, fitting into these ideal measures is rewarded (i.e. these people are treated better, they are given more opportunities and are considered healthier, smarter, happier, more successful and socially more competent), while those who do not fit those measures are stigmatized (11). Young people also need to be aware of the power of the media and learn how to view media with a critical eye. It is so because, once young people learn about overt media tactics, they will be empowered and experience media in a different way later in life (12). This cross-sectional study has been conducted among 278 participants, where 159 are students in medical vocational schools and 119 are students in a grammar school. When it comes to gender, the majority of the participants are females. Median age is 18 years for both schools and only a few students are 20 years old (Table 1). The majority students from medical vocational schools come from villages and the majority in grammar school are from towns (Table 1). In relation to that fact, it is noticed that medical students are less concerned about their physical appearance than the participants in the grammar school. Going through puberty can amplify body image concerns among boys and girls (13). Puberty for boys brings characteristics typically admired by society: strength, height, broadness. Puberty for girls, on the other hand, brings with it characteristics often perceived as less laudable, as girls generally get rounder and have increased body fat (14). Apart from gender differences, there are evidence that body image dissatisfaction grows during adolescent years what confirms our results. When it comes to gender, female participants are more concerned about their physical appearance than male participants in both schools, which is supported by general experience and statements in literature related to this topic (Table 2). The fact that there is only a small number of female participants who are worried about their physical appearance can be explained with the results on students' normal BMI. There is only a small number of overweight or underweight students (Figure 1). These results implify that most of adolescents live in a traditional environment, where young people live with their families and still consume traditional "mothers' everyday foodfood", so that $\mathrm{BMI}$ value is not so severely impaired.

In addition, the majority of students live in functional families (Table 4) which can affect the way they eat and amount of stress they experience. Individuals who have a positive attitude towards their physical appearance cannot be influenced by media, peer pressure or family (15). However, this does not mean that these individuals are not exposed to negative information from those sources. Nevertheless, they have tendencies not to take seriously these comments (15). When it comes to female participants who are worried about their physical appearance, it is important not to neglect their presence. It is possible that these individuals apply some methods for losing weight. In addition to increasing risk for negative consequences such as eating disorders, other cross-sectional and longitudinal research suggested that weight maintenance and dieting attempts are associated with other health-compromising behaviors, including poor nutrition, smoking and drinking $(16,17)$. All participants show low self-esteem (Table 3$)$ what can be explained by their adolescent youth, which is a time to search for personal identity and developing their own image about themselves. This is related to the fact that one's body image is related to their self-esteem and psychological and physical wellbeing. Therefore, a negative body image is related to low self-esteem, anxiety and depression (18). Low self-esteem thus seems to be a unique factor that makes adolescents susceptible to depression. The association between self-esteem and depressive 
symptoms is interesting to examine during adolescence, as self-esteem affects many of the developmental challenges adolescents have to deal with, such as identity formation and reshaping social relations $(19,20)$. Despite the exhibited low self-esteem, there is no confirmed association between body image dissatisfaction and low self-esteem (Table 3). In addition, there are some conflicted research results. Some research indicate that boys and girls will continue to experience body image dissatisfaction during adolescent years (21). On the other hand, others suggest that, during adolescent period, boys and girls become gradually satisfied with their physical appearance. Finally, there are those who suggest different developmental paths for adolescents where females become less satisfied and males more and more satisfied with their physical appearance (23). This indicates that it is necessary to investigate further the association between low self-esteem and body image satisfaction. This association could exist only in particular groups of young people and not necessarily in every adolescent group. In relation to this, results in this research do not show difference in particular sociodemographic characteristics, gender or type of school.

When it comes to self-evaluation of their nutritional status, medical students are not worried about their physical appearance and their estimation of their body matches the desired BMI. On the other hand, even dough not worried about their physical appearance, participants from grammar school have wrongly estimated their BMI to be lower than the desirable (Figure 2). Moreover, lower body weight among the participants from grammar school could be the result of higher levels of stress due to school obligations (working harder to achieve better grades and continue to higher levels of education) and latter due to alcohol consumption (Table 5).

When it comes to gender and excess body weight, female outnumber male participants. This can be explained by the fact that females mature faster when it comes to physical characteristics and by increased feeding as a method of stress release. It is highly possible that females develop problems related to their bodies when entering adolescent period (24). Furthermore, females are exposed to high amounts of sociocultural pressures to look a certain way (25). For screening or for epidemiologic research, the BMI is used to assess weight status in adolescents as well as adults. Whereas in adults the $\mathrm{BMI}$ cut points that define obesity and overweight are not linked to age and do not differ for males and females, in growing children BMI varies with age and gender. Since the quarter of participants made a mistake estimating their BMI, it is important to conduct more research among larger number of participants to verify the possible reasons for that result. It is possible that such results are a reflection of local or traditional understanding of physical beauty, which entail curves. These mistakes in estimation were more frequent in medical vocational school whose students come from villages. Morris Rosenberg analyzed how social context forms one's opinion of themselves. He claims that social comparison is related to a minority status and can have negative consequences on one's self-evaluation (26). On the other hand, male participants from grammar school made more mistakes in their estimations. This can be related to the latest trend that promotes lean and muscular male body (27) and to the fact that grammar school students are more under the influence of the media (or more informed on trends). It is evident that BMI measurements and BMI self-evaluation are not an adequate method for analyzing the participants because the participants, even those worried about their physical appearance, estimated their 
appearance in accordance with the desirable BMI. Body image dissatisfaction can be caused by other body characteristics apart from the body weight. Previous studies indicated many scales that quantitatively assess the body image concerns, where every scale has their own validity, reliability, and cultural norms. Since there are few reliable tool to analyze nutritional status, Tayaba Moeen et al. have pointed out the need for further assessment of body image concerns and to define how individuals perceives or thinks about their physical appearance. Body Image Scale, containing 35 items, highlighted the three of the additional components of body image, namely; physical component, psychological component and strategies to use to maintain one's body image which had not been discussed in previous scales (28).

When it comes to residency, majority of participants in medical vocational school come from villages and participants in grammar school come from both villages and town (Table 2). Traditional way of life can have impact on the idea how a perfect body should look. In that sense, it is noticed that children raised in such surrounding have a different understanding of the perfect boy measures than the one in the westernized cultures (29).

Furthermore, when it comes to family and its influence, living with both parents with a stable marriage can affect children in a positive sense when it comes to their body image concern. There are also some indications that body image could be affected by the parents' education or socio-economic status although it is currently not thoroughly investigated (30). In addition, previous studies confirmed that living in a less populated area, or having parents with primary education, was uniquely related to a more negative body image, which comports with other studies of older children and adolescents (31). Nevertheless, it is very important to educate children on physical appearance and its changes during puberty. This means that at a very young age, children need to understand that each body is different in size and shape. It is a message that all need to understand and accept from the beginning of their lives. Young people need to understand both physical and emotional changes they experience in puberty and they need to be aware that those changes are a normal part of their development. In order to cultivate a healthy body image, adolescents need to obtain a set of skills that will help them go through the numerous ideas on how to look and how to eat.

Despite the fact that the results of this research indicate that majority of participants are not severely concerned about their body image, it is very important not to ignore those who do worry about their body image. Also, our results implify that traditonal parenting may be a protective factor in process of development. In those with low body image, it can be associated more with existential fear (study sucess) or with a preoccupation with one's own appearance.

According to the approach of social comparison, the risk of body image dissatisfaction is greater with those who compare themselves to others than with those who rarely compare themselves to others.

It is so because the negative body image they have could have repercussions for their psychological wellbeing, eating habits, nutritional status, and overall quality of life. Programs that educate adolescents on possible risks a negative body image have could contribute to adolescent health and well-being by 
promoting realistic and age-appropriate body images and promoting tolerance and diversity. There is currently no official service in Croatia where adolescents could find more information how to provide better control of self- esteem, which affects many of the developmental challenges.

\section{Conclusions}

Female participants attending both schools show a lower level of body image dissatisfaction compared to male respondents. Male respondents attending both schools have a decreased level of self-esteem. The research established a linear correlation between the body image satisfaction and gender of the students in both schools. An association between level of body image satisfaction and self-esteem was not established, while Adolescents in in Eastern Croatia are not overly concerned about their physical appearance despite relatively decreased self-esteem. A lack of association between reduced self-esteem and self-assessment of appearance may also be a consequence of later sexual maturation and tradional development which promote the traditional values of family, youth life and marriage. Early detection of a negative body image could provide a better control over self- esteem and promote psychological support later. Our results indicate importance of large studies with more participants in order to find more precise information of better control of self- esteem.

\section{List Of Abbreviations}

BMl: body mass index

\section{Declarations}

Ethical approval. This study is approved by the Ethics Committee, Faculty of Medicine, Josip Juraj Strossmayer University of Osijek. CLASS:602-04/17-08/12, REG:

21589-61-07-17-73.

Conset form for Publication. The authors declare that questionnaire on socio-economic status of the students has been filled anonymously, and anonymity can be guaranteed.

Availability of supporting data. Due to nature of this study, all participants agree for their data to be shared publicly, so supporting data is available.

Competing interests. The authors declare no conflict of interest. The funders had no role in the design of the study; in the collection, analyses, or interpretation of data; in the writing of themanuscript, or in the decision to publish the results.

Funding: This study received no external funding. The article processing charge (APC) was

funded by Faculty of Dental Medicine and Health, Osijek, Croatia. 
Authors' contribution. Zvonimir Bosnic and Ljiljana Trtica Majnaric were responsible for conceptualization and design of the study. Maja Miletic, Mile Volaric, Nikola Volaric performed the investigation and collected data. In addition, they were responsible for data validation. Zvonimir Bosnic and Dubravka Holik provided participants with data. Ljiljana Trtica Majnari supervised the study. Zvonimir Bosnic wrote the manuscript. Dubravka Holik and Ljiljana Trtica Majnaric reviewed and edited manuscript. All authors have read and agreed on the published version of the manuscript

Acknowledgments: The authors would like to acknowledge Barbari Trbojević, student of faculty of dental medicine and health, for her help in data collection. Her name is included with her permission in this acknowledgment section.

\section{References}

1. Gallagher SM. The influence of social media on teens' self-esteem. Theses and Dissertations. 2017. Available on: https://rdw.rowan.edu/etd/2438/. Accesed 03 May 2020.

2. Pokrajac-Bulian, A., Živčić-Bećirević, I., Vukmanović, S., Forbes, G. ( 2005). Psihologijske teme (2005), Volumen 14 broj 1: 57-70.

3. Dunkley TL, Wertheim EH, Paxton SJ. Examination of a model of multiple sociocultural influences on adolescent girls' body dissatisfaction and dietary restraint. Adolescence. 2001;36(142):265-279

4. Durkin SJ, Paxton SJ, \& Sorbello M. An Integrative Model of the Impact of Exposure to Idealized Female Images on Adolescent Girls' Body Satisfaction. Journal of Applied Social Psychology 2007, 37(5):1092 - 1117.

5. Hendel A. Restoring Self-Esteem in Adolescent Males. The International child and youth care network. (CYC-Net). Availabe on: https://www.cyc-net.org/cyc-online/cyconline-jan2011-hendel.html. Accessed: 03 May 2020.

6. Dittmar H, Halliwell E and Stirling E. Understanding the Impact of Thin Media Models on Women's Body-Focused Affect: The Roles of Thin-Ideal Internalization and Weight-Related Self-Discrepancy Activation in Experimental Exposure Effects. Journal of Social and Clinical Psychology, 2009; 28(1), 43-72.

7. Reilly JJ. Diagnostic ability of the BMI for age in pediatrics. Int J Obes Relat Metab Disord,2006; 30: 595-597.

8. Must A, Anderson E. Body mass index in children and adolescents: considerations for populationbased applications. International Journal of Obesity, 2006; 30, 590-594.

9. Campbell MJ. Statistics at saquare two, second edition. 2006, Oxford: Blackwell Publishing.

10. Stang J, Story M (eds). (2005). Guidelines for Adolescent Nutrition Services . Availabe on: http://www.epi.umn.edu/let/pubs/adol_book.shtm. Accessed: 03 May 2020.

11. Tiggeman M. Sociocultural perspectives on human appearance and body image. In T. F. Cash \& L. Smolak (Eds.), Body image: A handbook of science, practice, and prevention (2nd ed., pp. 12-19). 2011; New York, Guilford Press. 
12. Tiggemann M, Pickering AS. Role of television in adolescent women's body dissatisfaction and drive for thinness. Int J Eat Disord, 1996; 20(2):199-203.

13. Levine M, Smolak L. Cultural influences on body image and the eating disorders. In W. S. Agras (Ed.), The Oxford handbook of eating disorders, (pp. 223-246). 2010; Oxford: Oxford University Press.

14. O'Dea JA, Abraham S. Onset of disordered eating attitudes and behaviors in early adolescence: interplay of pubertal status, gender, weight, and age. Adolescence, 1999; 34 (136):671-679.

15. Frisén A, Holmqvist $K$. What characterizes early adolescents with a positive body image? A qualitative investigation of Swedish girls and boys. Body Image, 2010; 7, 205-212.

16. Larson NI, Neumark-Sztainer D and Story M. Weight control behaviors and dietary intake among adolescents and young adults: Longitudinal findings from Project EAT. Journal of the American Dietetic Association, 2009; 109(11), 1869-1877.

17. Pirkle EC, Richter L. Personality, attitudinal and behavioral risk profiles of young female binge drinkers and smokers. Journal of Adolescent Health, 2006; 38(1), 44-54.

18. Kostanski M, Gullone E. Adolescent body image dissatisfaction: Relationships with self-esteem, anxiety and depression controlling for body mass. Journal of Child Psychology and Psychiatry, 1998; $39,255-262$.

19. Steinberg L, Morris AS.Adolescent development. Annual Review of Psychology, 2010; 52:83-110.

20. Masselink M, Van Roekel E, Oldehinkel AJ. Self-esteem in EarlyAdolescence as Predictor of Depressive Symptoms in Late Adolescence and Early Adulthood: The Mediating Role of Motivational and Social Factors. J Youth Adolesc,2018; 47(5):932-946.

21. Eisenberg ME, Neumark-Sztainer D, Paxton S. Five-year change in body satisfaction among adolescents. Journal of Psychosomatic Research,2006; 61, 521-527.

22. Friestad C, Rise J. A longitudinal study of the relationship between body image, self-esteem and dieting among 15-21 year olds in Norway. European Eating Disorders Review, 2004; 12(4), 247-255.

23. Bearman SK, Presnell K, Martinez E, Stice E. The skinny on body dissatisfaction: A longitudinal study of adolescent girls and boys. Journal of Youth and Adolescence, 2006; 35, 229-241.

24. Tiggemann M. Body image across the adult life span: Stability and change. Body Image,2004; 1, 2941.

25. Matias TS, Rolim MK, Kretzer FL, Schmoelz CP, Andrade A. Corporal satisfaction associated with physical activity practice during adolescence. Motriz,2010; 16:370-8.

26. Rosenberg, M. Contextual dissonance effects: Nature and causes. Psychiatry, 1977; 40, 205-217.

27. Presnell K, Bearman SK, Stice E. Risk factors for body dissatisfaction in adolescent boys and girls: a prospective study. Int J Eat Disord, 2004; 36:389-401.

28. Moeen T, Muazzam A, Zubair B. Development and Validation of Body Image Scale (BIS) For Young Adult Females. Pakistan Journal of Social and Clinical Psychology, 2013; Vol. 11, No.1, 52-58.

29. Becker, AE. Body, self, and society: The view from Fiji, Philadelphia; University of Pennsylvania, 2019. 
30. Austin SB, Haines J, Veugelers PJ. Body satisfaction and body weight: Gender differences and sociodemographic determinants. BMC Public Health, 2009; 9, 313-319.

31. Al Sabbah H, Vereecken CA, Elgar FJ, Nansel T, Aasvee K, Abdeen Z. et al. Body weight dissatisfaction and communication with parents among adolescents in 24 countries: International cross-sectional survey. BMC Public Health, 2009; 9:52.

\section{Figures}

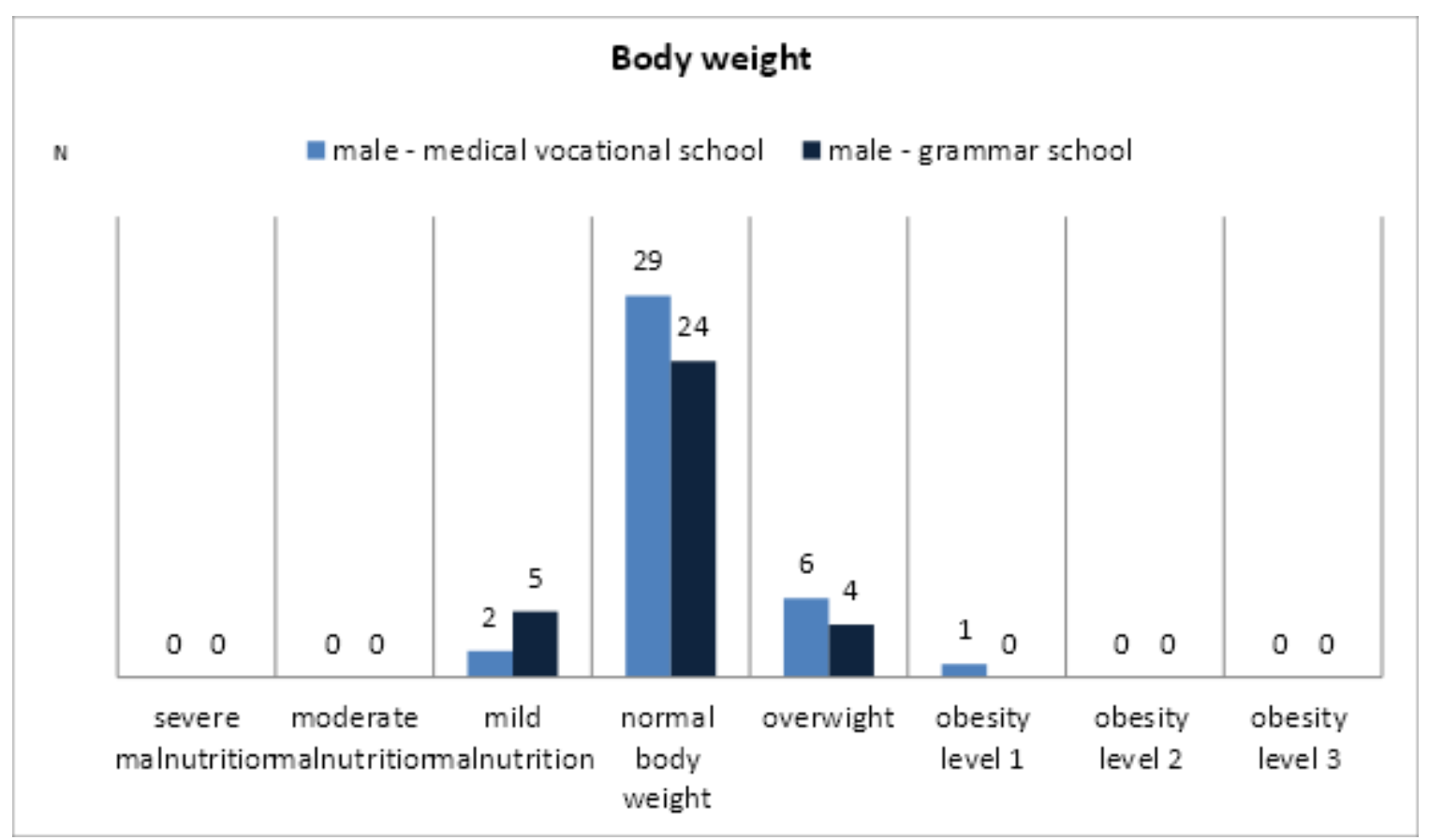

\section{Figure 1}

Body weight among male participants 


\section{Body weight}

$$
\text { \#female - medical vocational school घfemale-grammar school }
$$

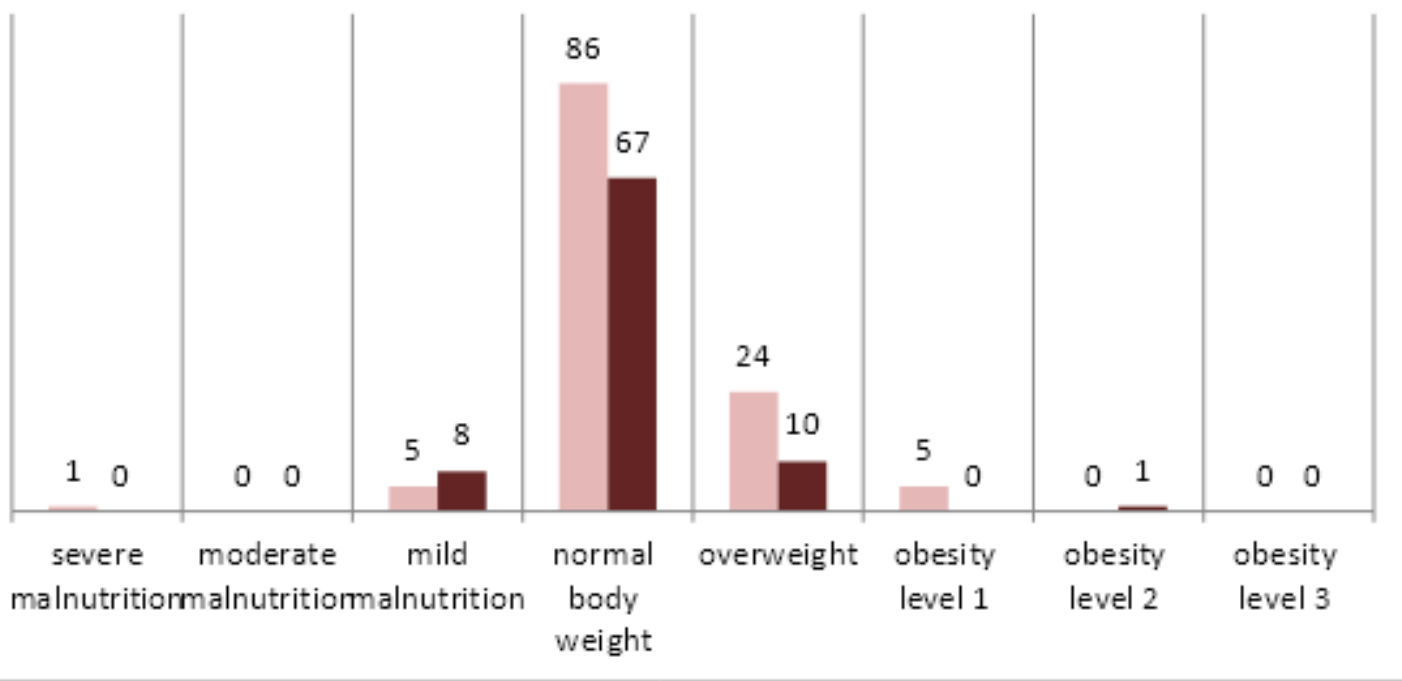

Figure 2

Body weight among female participants

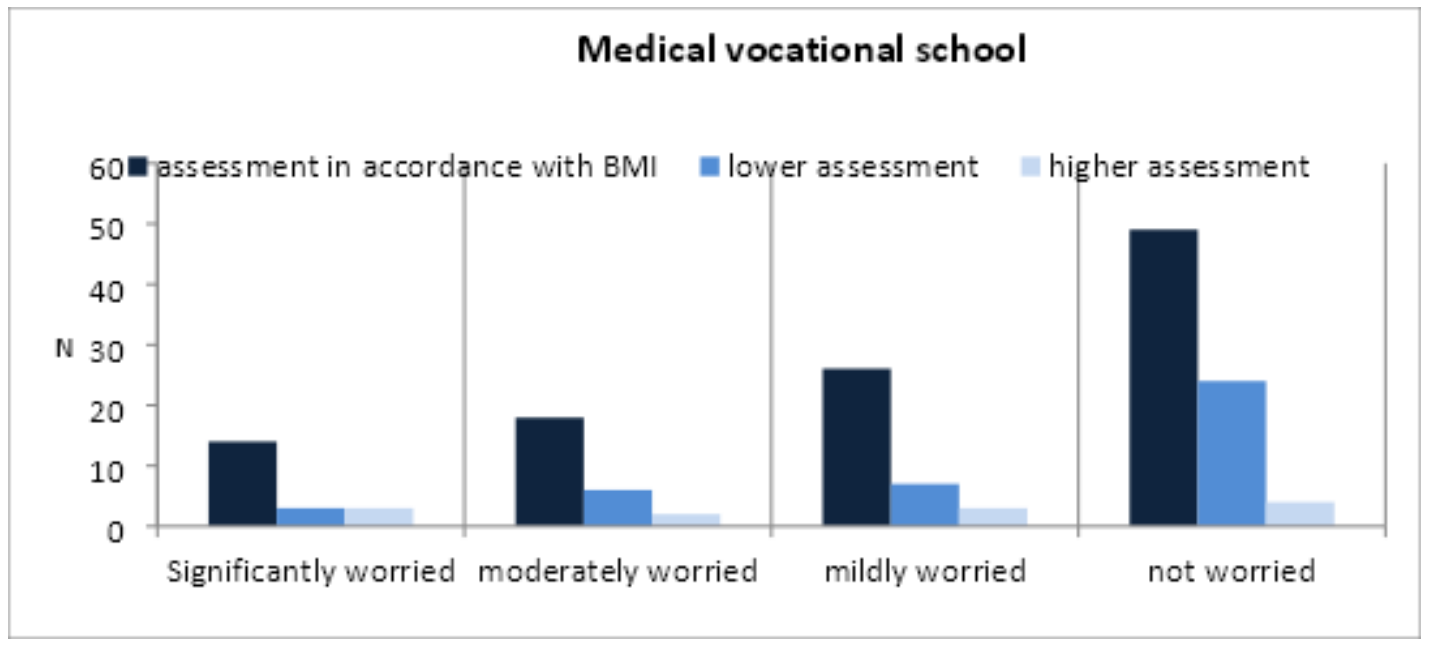

\section{Figure 3}

Body Image Questionnaire 


\section{Grammar school}

assessment in accordance with BMI lower assessment higher assessment

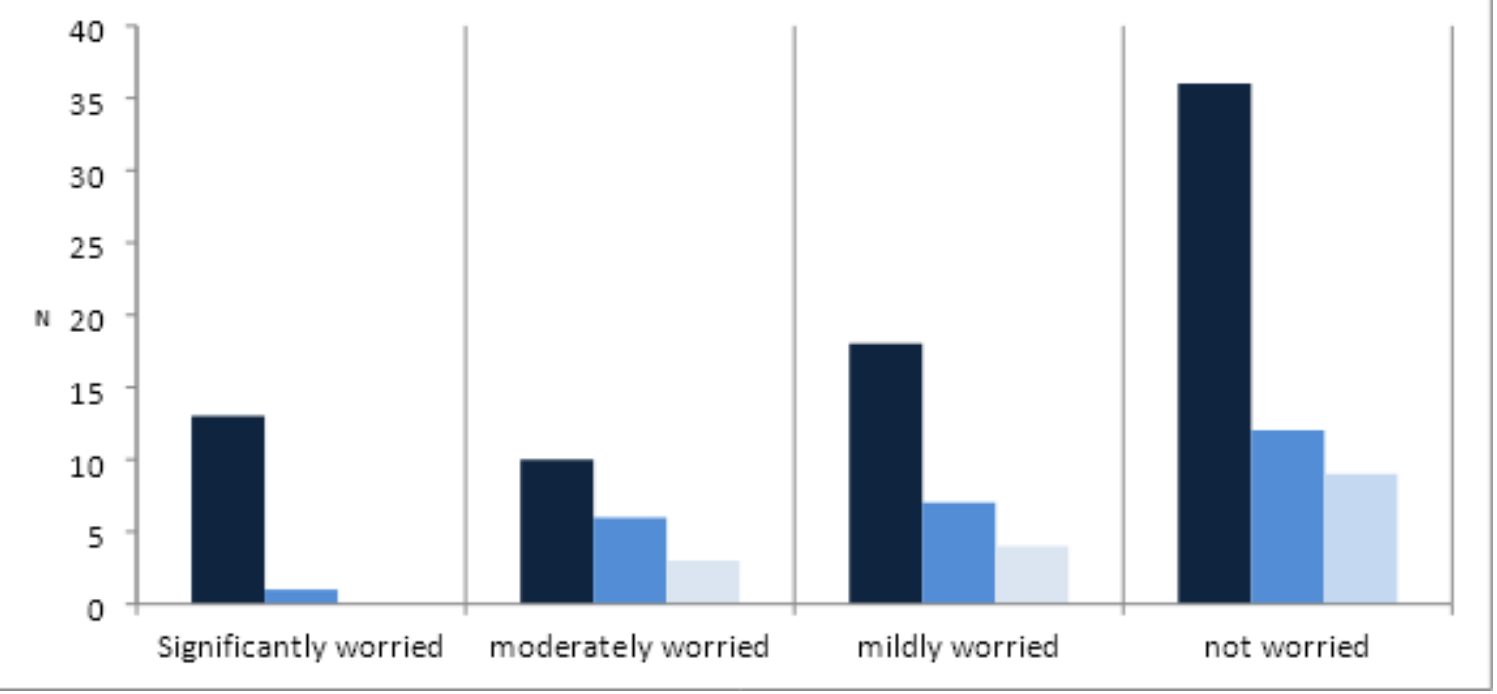

\section{Figure 4}

Body Image Questionnaire 